\title{
Serotonergic Facilitation of Quantal Release at Central Inhibitory Synapses
}

\author{
Isabelle Mintz ${ }^{\mathrm{a}}$ and Henri Korn \\ INSERM U261, Neurobiologie Cellulaire, Institut Pasteur, 75724 Paris Cedex 15, France
}

The teleost Mauthner (M)-cell is subjected to a powerful glycinergic inhibition that regulates its threshold for initiation of a vital escape reflex. The effects of 5-HT on this inhibition were studied in current- and voltage-clamp experiments because the $\mathbf{M}$-cell and its afferents have a profuse serotonergic innervation, including axoaxonal contacts with terminals of the inhibitory interneurons. Local applications of the amine and/or of its uptake blockers markedly enhanced inhibitory currents evoked by synchronous activation of two identified presynaptic networks.

In order to determine the site of this 5-HT action, we exploited the fact that in the M-cell, synaptic noise is predominantly inhibitory. Furthermore, its quantal components can be resolved providing a means to distinguish pre- and postsynaptic loci underlying variations in synaptic efficacy. As in other cell types, it consists of spontaneous exocytotic events and multiquantal responses triggered by action potentials in afferent neurons. 5-HT or its uptake blockers produced a long-lasting enhancement of this noise, manifested as a shift to the right of amplitude distribution histograms of the individual inhibitory postsynaptic currents (IPSCs) and an increase in the mean quantal content of noise. In contrast, the size of the miniature IPSC (mIPSCs) remained constant in these experiments and in another series where 5-HT was given in presence of TTX. In this case, the amine also increased the rate of occurrence of single quanta.

Taken together, these data indicate that 5-HT acts presynaptically to increase the probability of evoked and spontaneous release of glycine. This conclusion was reinforced by evidence that the overall frequency of the responses in noise could be unaltered by $5-\mathrm{HT}$, indicating that the afferent firing pattern had remained constant.

Extracellular recordings of the presynaptic volleys showed that action potentials were not prolonged and suggested that 5-HT closes $\mathrm{K}^{+}$channels in the terminal membrane, leading to an increase of resistance and a larger depolarization in that region as a possible mechanism for the facilitation of release.

While the enhancement of transmitter release persisted

\footnotetext{
Received Feb. 27, 1991; revised May 24, 1991; accepted May 30, 1991.

We thank Dr. D. S. Faber (University of Buffalo) for his encouragement and help in the course of this work.

Correspondence should be addressed to Henri Korn, INSERM U261, Neurobiologie Cellulaire, Institut Pasteur, 25 Rue du Dr-Roux, 75724 Paris Cedex 15, France.

a Present address: Department of Neurobiology, Harvard Medical School, 220 Longwood Avenue, Boston, MA 02115.

Copyright $\odot 1991$ Society for Neuroscience $0270-6474 / 91 / 113359-12 \$ 05.00 / 0$
}

for $\mathbf{2 0}$ min or more, there was also a transient induction of a $\mathrm{K}^{+}$inward-rectifying current in the $\mathrm{M}$-cell.

These results indicate that $5-\mathrm{HT}$ increases the efficacy of inhibitory synaptic transmission in the vertebrate CNS by a presynaptic action.

The amine 5-HT can influence activity patterns within neuronal networks by acting at distinct sites, that is, at voltage-dependent somadendritic conductances and at presynaptic terminals. While a multiplicity of actions have been reported at neuronal cell bodies (for review, see Klein et al., 1982; Colino and Halliwell, 1987; Hounsgaard et al., 1988; Yakel et al., 1988; Bobker and Williams, 1989, 1990a; Hounsgaard and Kiehn, 1989; Berger and Takahashi, 1990; Sah, 1990), there are few well-documented examples of its direct effect on synaptic function, particularly in the vertebrate CNS, where afferent terminals are not accessible. In the two invertebrate preparations studied most extensively, namely, crustacean neuromuscular junction (Glusman and Kravitz, 1982; Finger and Martin, 1984; Dixon and Atwood, 1989a) and a sensorimotor synapse in Aplysia (Kandel et al., 1981; Dale and Kandel, 1990), 5-HT produces a longlasting facilitation of release, although more than one mechanism may be involved. Increased release at the Aplysia synapse is in part associated to a broadening of presynaptic impulses due to a cAMP-mediated closure of $\mathbf{K}$ channels (Klein and Kandel, 1978, 1980), whereas, in crayfish, presynaptic action potentials are not prolonged, and separate second messengers are postulated to underly the early and late phases of this process (Dixon and Atwood, 1989a,b; Goy and Kravitz, 1989). A necessary tool for assessing a presynaptic locus of modulation would be quantal analysis of evoked and spontaneous release, which is difficult in the CNS, particularly with in vivo preparations.

The teleost Mauthner (M)-cell, a reticulospinal neuron that triggers a vital escape reaction in fish, provides a favorable model for such studies for several reasons. It has a profuse serotonergic innervation (Fig. $1 A$ ) that, in addition, incudes axoaxonic contacts with the endings of identifiable inhibitory interneurons known to be glycinergic (Mintz et al., 1989). These interneurons, which can be activated selectively, project primarily to the $\mathrm{M}$-cell soma, and their presynaptic volley is readily recorded extracellularly, due to high resistivity and passive impulse propagation in that region (Furshpan and Furukawa, 1962).

For this study, we also took advantage of the fact that synaptic noise in the $\mathbf{M}$-cell soma is predominantly inhibitory and glycinergic and that its quantal components can be resolved (Korn et al., 1987; Korn and Faber, 1990a). As in all neurons, this stochastic activity contains both spontaneous and evoked responses, which correspond respectively to asynchronous and 


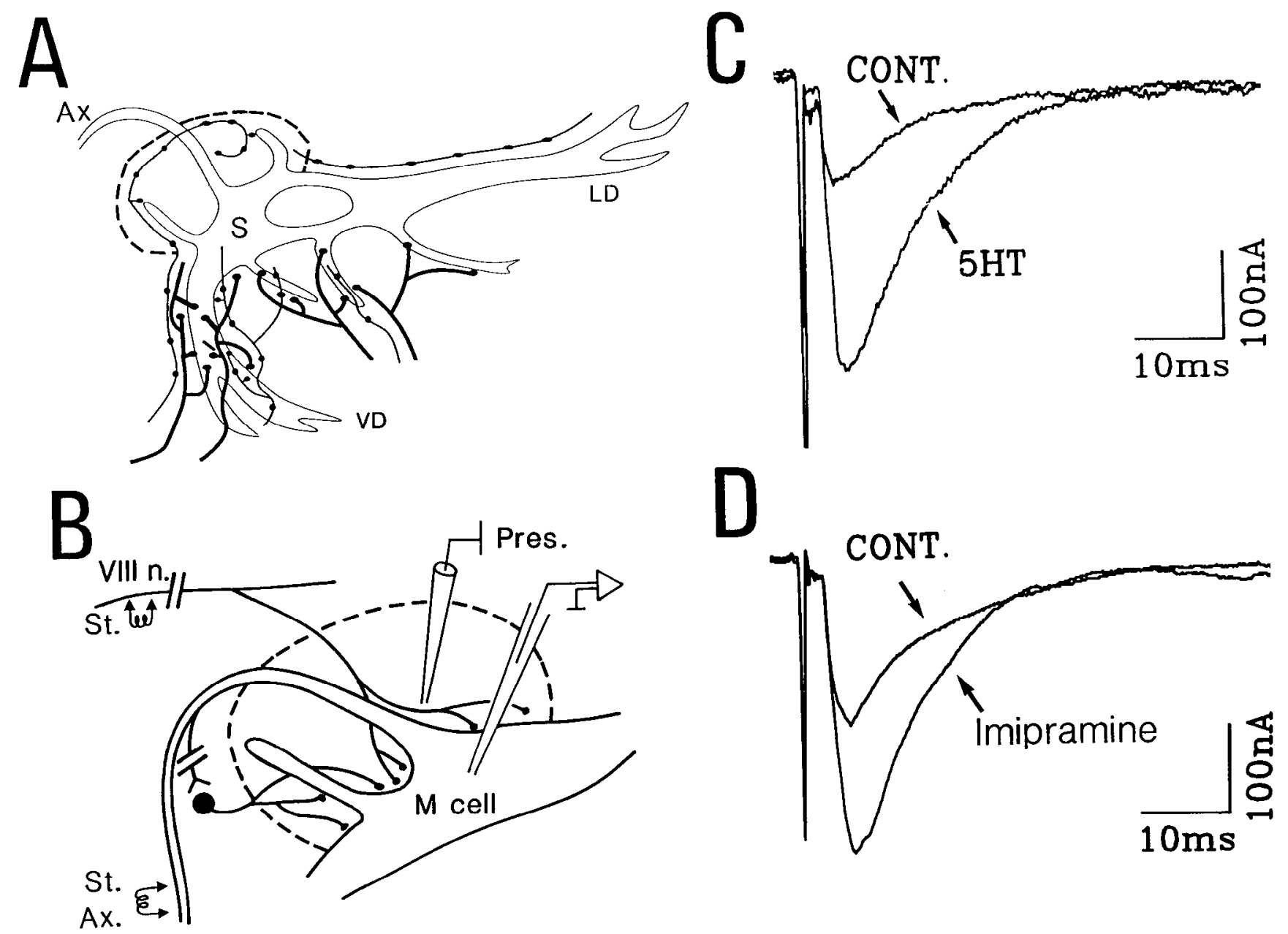

Figure 1. Enhancement of evoked inhibition by 5-HT. A, Schematic drawing of the M-cell's serotonergic innervation, revealed by immunocytochemistry. Two classes of fibers are illustrated, large ones that impinge on the primary and small dendrites, and thin beaded axons found in the axon cap and near the lateral dendrite (modified from Gotow et al., 1989). B, Experimental setup. Intracellular recordings were obtained from the soma of the M-cell. 5-HT or its uptake blockers, such as imipramine or fluoxetine, were pressure injected in the axon cap (broken line) through a second micrnelectrode close to the M-cell membrane. Two types of glycinergic neurons could be activated, the collateral ones via antidromic stimulations of the M-cell axon (St. Ax.), or commissural interneurons after stimulations of the contralateral VIIIth nerve (VIII $n$. St.). $C$ and $D$, Enhancement of the collateral IPSC by 5-HT $(C)$ and imipramine $(D)$. In both cases, the M-cells were stably loaded with chloride ions and were voltage clamped at resting membrane potential $(-85$ and $-74 \mathrm{mV}$, respectively; chopping frequencies, 22 and $16 \mathrm{kHz})$. Cont., control.

spike-triggered exocytosis (Granit and Phillips, 1956; Eccles et al., 1961; Katz and Miledi, 1963; Alger and Nicoll, 1980). Each synaptic potential (or current) that builds up noise represents either single quanta released at a single active zone, or multiquantal responses, due to simultaneous release of several such units from different sites within a given connection (Korn and Faber, 1987). Thus, their relative number and amplitude distributions provide means for comparing presynaptic parameters of quantal release under different physiological conditions.

In preliminary publications, we briefly reported a presynaptic facilitation of both evoked and spontaneous glycinergic transmissions by 5-HT (Mintz and Korn, 1989; Mintz et al., 1989). We provide here a detailed analysis of the pre- and postsynaptic actions of this amine. Its uptake blockers were used in order to demonstrate the role of endogenous 5-HT. Our data provide evidence for an increased probability of release at central inhibitory synapses that can persist over $30 \mathrm{~min}$, that is, beyond the initial period of elevated 5-HT concentration. They suggest that as with excitation, inhibition can be regulated through local presynaptic interactions.

\section{Materials and Methods}

Electrophysiological procedures. Experiments were performed in vivo on goldfish (Carassius auratus) perfused through the mouth with aerated water containing $70 \mathrm{mg} /$ liter of 3-aminobenzoic acid ethyl ester (MS222) for anesthesia. They were further immobilized with $D$-tubocurarine injected intramuscularly $(1 \mathrm{mg} / \mathrm{gm}$ body weight).

The Mauthner cell, identified by its antidromic response to spinal stimulation, was recorded from with $\mathrm{KCl}(2.8 \mathrm{M})$ - or K-acetate $(4 \mathrm{M})$ filled electrodes of low (2-4 M $\Omega$ ) resistance. Current-clamp and singleelectrode voltage-clamp (SEVC; sampling frequency ranging from 15 to $22 \mathrm{kHz}$ ) recordings were obtained using an Axoclamp 2 (Axon Instruments). The axon cap was first located on the basis of the large-amplitude $(10-20 \mathrm{mV})$ extracellular field potential generated there by the antidromic spike (Furshpan and Furukawa, 1962), and the electrode was then inserted laterally in the soma.

As shown in Figure $1 B$, a second pipette placed in the cap and within 20-50 $\mu \mathrm{m}$ above the M-cell membrane was used for local pressure injections (four to eight pulses of $30 \mathrm{msec}$ duration applied within 10 sec) of 5-HT (2-5 mm) or 5-HT uptake blockers, that is, imipramine $(20 \mu \mathrm{M})$ and fluoxetine $(10 \mu \mathrm{M})$. These compounds were dissolved in a $130 \mathrm{~mm} \mathrm{NaCl}, 10 \mathrm{~mm}$ HEPES solution adjusted to $\mathrm{pH} 7.2$ with $\mathrm{NaOH}$. The pipette was withdrawn immediately after the injection to avoid uncontrolled leakage of the solutions. 

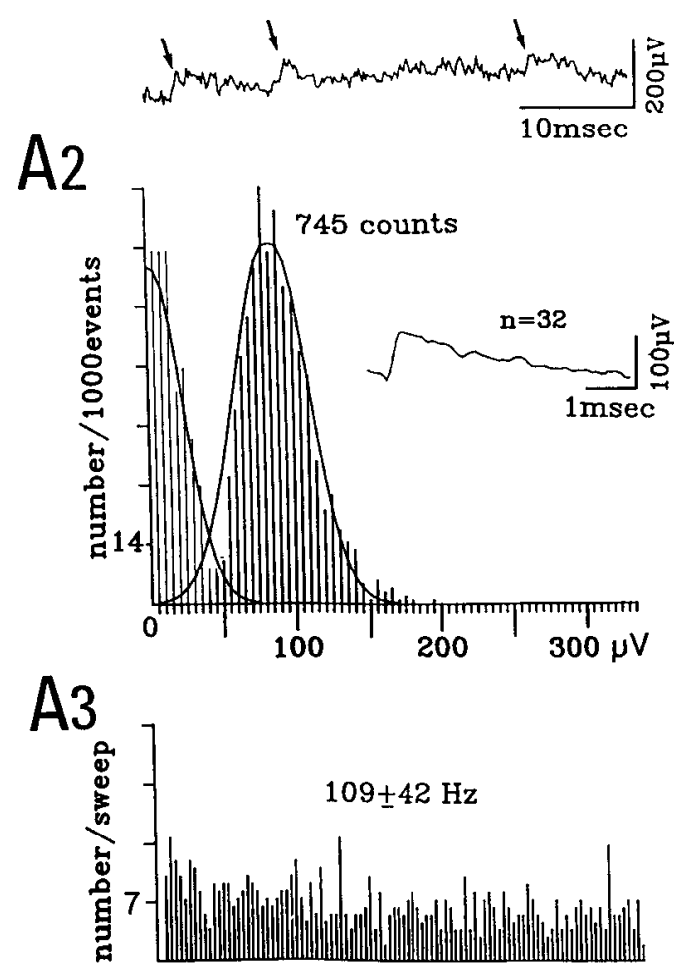

$68 \mathrm{msec}$ per sweep
Figure 2. Frequency and distribution of impulse-independent inhibitory quanta, before and after 5-HT. $A 1-A 3$, Control current-clamp recordings obtained in presence of TTX $(20 \mu \mathrm{M})$ in a chloride-loaded M-cell (resting membrane potential, $-75 \mathrm{mV}$ ). A1, Sample sweep with spontaneous mIPSPs (signaled by arrows). A2, Amplitude distribution of 745 mIPSPs with Gaussian fit $(84 \pm 23 \mu \mathrm{V}$, mean $\pm \mathrm{SD}$; right peak) and of background fluctuations (SD = $21 \mu \mathrm{V}$; represented for positive values). Inset, Average of 32 quantal events. A3, Time distribution of mIPSPs. Their number was counted in successive sweeps, and as indicated the corresponding frequency, averaged $109 \pm 42$ $\mathrm{Hz}$ (mean $\pm \mathrm{SD}$ ). $B 1-B 3$, Same presentation as above, of data obtained after local application of 5-HT, B1, Increased occurrence of mIPSPs; note that they were distinguished, on the basis of their time course, from occasional spontaneous excitatory potentials $(*)$. $B 2$, Evidence that the size and time course of mIPSPs and the distribution of background noise were not altered by the amine. The amplitude of 1078 events was distributed as in $A 2(84 \pm$ $25 \mu \mathrm{V}$, mean $\pm \mathrm{SD}$ ). $B 3$, Increased rate of mIPSPs, which averaged $155 \pm 50$ $\mathrm{Hz}$ (same calibration as in $A 3$ ). Note that in $A 2$ and $B 2$ the SD of the quantum $(\sigma q)$ is slightly larger than that of the background noise $(\sigma n)$. From cell 2 of Table 1 .
In experiments conducted with $\mathrm{KCl}$ electrodes, chloride-mediated synaptic events were manifest as depolarizations (in current-clamp recording mode) or inward-going currents (in SEVC) due to the internal loading of the $\mathrm{M}$-cell with chloride ions. The steady-state chloride gradient was estimated from the stable amplitude of the collateral IPSP (Faber and Korn, 1982) produced by activation of the recurrent collateral network following M-cell antidromic firing. Stimulation of the contralateral VIIIth nerve, which excites a second set of glycinergic afferents by way of the commissural interneurons (Faher and Korn, 1978), was also used.

Recordings of field potentials in the axon cap were provided by lowresistance K-acetate electrodes $(0.2$ and $0.5 \mathrm{M} \Omega)$. The constancy of the size of the negative extracellular antidromic M-cell spike was taken as a criterion indicating that the extracellular resistance within the axon cap was not changed by 5-HT, a crucial notion for our analysis of this amine's effect on afferent volleys.

Data were stored on magnetic tape (four-channel Racal recorder, $8-\mathrm{kHz}$ bandwidth frequency) or video tape after a $44 \mathrm{kHz}$ analog-digital conversion (PCM4, Medical Systems Corporation). Triggered events, such as voltage step-induced currents or synaptic responses, were analyzed on an IBM PC using pCLAMP software. Spontaneous synaptic activity was analyzed on a DEC $11 / 23$ computer after digitization at 6$8 \mathrm{kHz}$ sampling rates, using an INDEC data acquisition system.

Quantal components of synaptic noise. On the basis of the stability of the chloride gradient, and of the signal to background noise ratio, 10 out of 28 chloridc-loaded M-cells were selected for an extensive analysis of their spontaneous synaptic noise, in current-clamp or in SEVC mode. The method used for measuring the amplitudes of individual events comprising noise is an extension of that used previously to extract quanta in voltage-clamped M-cells that were not chloride loaded. In that case, depolarizing steps were used to isolate outward-going IPSCs, and it was found that in these neurons spontaneously occurring synaptic noise is predominantly inhibitory. In the present work, the responses were either depolarizing IPSPs or inward currents recorded at resting potential, but the measurement and detection paradigms were the same (Korn et al., 1987; Korn and Faber, 1990a). The amplitude of each spontaneous synaptic response was measurcd from bascline to peak. In case of overlapping events, the baseline was obtained by extrapolating the exponential decaying phase of the preceding responses (Faber and Korn, 1980, 1982). The threshold for detection was close to twice the standard deviation of the background noise. The latter was measured in quiet periods where it appeared that there were no synaptic events The positive-going halves of a typical background noise distribution are shown in Figure 2, $A 2$ and $B 2$. Under those conditions, the assumption was that only a small fraction of the putative monoquantal components was lost in the background activity (Korn et al., 1982). This notion is confirmed by comparing the noise and monoquantal distributions in the same figures. The resulting amplitude distribution histograms, in which it seemed that relatively few small-amplitude events were missing (Figs. 3A3,B3, $4 B$ ), were normalized to the total number of events. The frequency of spontaneous events was computed independently by plotting their number, measured in successive sweeps of equal duration versus time.

Probability density functions used to fit the amplitude distributions were generated in two steps. The dominant first peak of a histogram, which corresponds to the population of single quanta (Korn et al., 1987), was approximated by a Gaussian function with values for its mean and standard deviation $\sigma q$ that minimized $X_{2}$ values. The complete histogram was then fit with a sum of Gaussian curves with the same standard deviation and mean amplitudes that were integral multiples of that of the first peak $(1 q, 2 q, 3 q, \ldots, n q)$. As already indicated (Korn and Faber, 1990), this protocol, which is based on the concept that noise is quantal, may permit visualization of subsequent larger classes, which may otherwise be obscured by the intrinsic variability of quantal size. This last factor might increase the standard deviation of the associated Gaussian distributions depending on the relative magnitudes of the variances within and between synaptic releasing sites. This approach was checked in four cells. In these experiments, miniature events were isolated at the end of the recording session by blocking all spike-dependent components with TTX $(20 \mu \mathrm{M}$; bathing the surface of the third ventricle to allow maximum diffusion and reach all networks). In confirmation, the amplitude distribution of synaptic noise in the absence 


\section{A1 CONTROL}

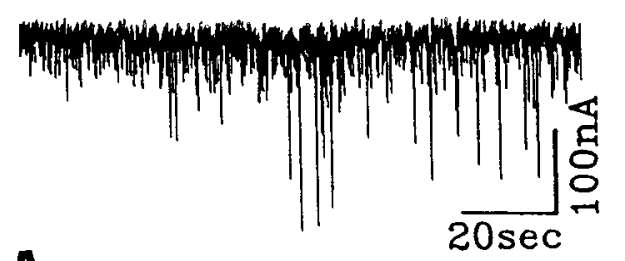

A2

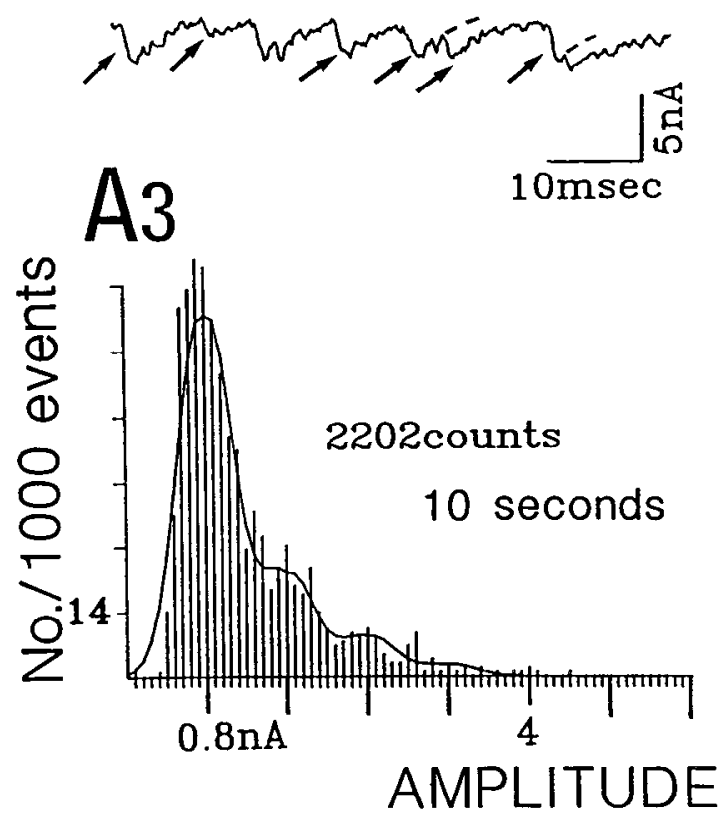

\section{B1 FLUOXETINE}

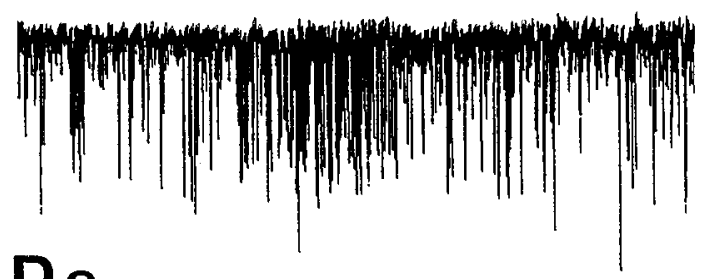

B2

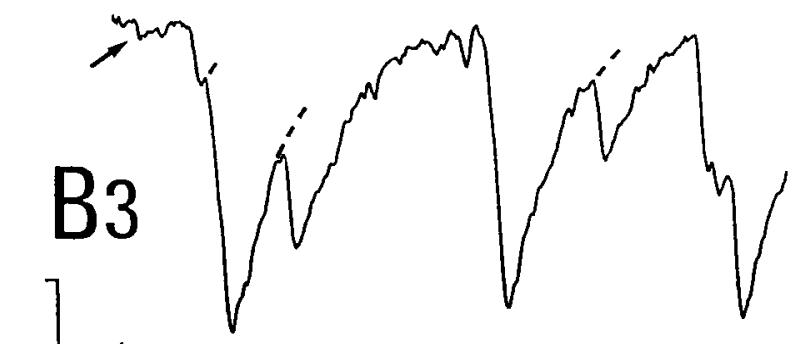

2403 counts

10 seconds

Figure 3. Enhancement of glycinergic synaptic noise by a 5-HT uptake blocker. $A 1-A 3$, Control data from a chloride-filled M-cell that was voltage clamped at resting membrane potential $(-72 \mathrm{mV}$; chopping frequency, $16 \mathrm{kHz})$. A1, Sample sweep of spontaneous inward-going synaptic currents. $A 2$, Expanded segment from $A 1$ showing that small events further identified as single quanta (arrows) could be distinguished from background fluctuations. A3, Amplitude distribution of the 2202 IPSCs identified throughout a period of $10 \mathrm{scc}$; isolated currents were measured from baseline to peak, while overlapping events were measured from the corrected decaying phase (broken curves) of the preceding response to their peak, as also shown in $A 2$ and $B 2$. The curve is the sum of four Gaussian functions having the same SD $(0.25 \mathrm{nA})$, and means separated by an amount equal to multiple values of the first one $(0.8 \mathrm{nA})$. Use of this fitting paradigm was based on the assumption that synaptic noise has a quantal structure. $B I-B 3$, As in $A 1-A 3$, but $8 \mathrm{~min}$ after a brief $(30-\mathrm{msec})$ local application of fluoxetine $(10 \mu \mathrm{M})$. Note that the largest components of synaptic noise became more numerous than in the control, in contrast to the presumed miniature IPSCs (arrow). The total number of events measured over a period of $10 \mathrm{sec}$ was unchanged, whereas the amplitude histogram is now fit with the sum of nine Gaussians due to the advent of the largest IPSCs. From cell 17 of Table 2.

of evoked release, and hence probably consisting only of single quantum responses, matched the first peak of the compound histograms. Finally, the last discernible group was defined as that including at least $2 \%$ of the total number of responses, which was always $>1000$.

As mentioned, the fits including several Gaussians neglected the intrinsic variability of the quantum size since (1) quantal variance has been found to be small (Korn and Faber, 1990a) and (2) there is no a priori rationale to assume that it is the same at all sites, rather than reflecting differences within distributed synapses (Triller et al., 1990). Nevertheless, this procedure provides a simple method for estimating the maximum number of classes and their quantal content, provided that the first one is well defined, given the preponderance of small events and/or its clear isolation with TTX.

\section{Results}

Of a total of 63 experiments, 38 were designed to investigate the postsynaptic actions of 5-HT $(n=33)$ and/or the modulation of glycinergic transmission $(n=28)$. Spontaneous miniature potentials isolated with TTX were studied in 13 other experiments, while the remaining 12 dealt with extracellular recordings of the presynaptic volleys. In each series, injections of 5-HT uptake blockers imipramine or fluoxetine were used to raise the external concentration of 5-HT released in vivo by serotonergic afferents for comparison of their effects with those of exogenous 5-HT

\section{Endogenous modulation of stimulus-evoked inhibitory currents}

Figure $1, C$ and $D$, is typical of the results obtained in this work with antidromic activation of the recurrent collateral network, which causes synchronous excitation of a pool of inhibitory interneurons. In all cases following applications of either 5-HT $(n=28$; Fig. $1 C)$, fluoxetine $(n=3)$, or imipramine $(n=7$; Fig. $1 D)$, the collateral IPSC was enhanced $(+103 \pm 21 \%$, mean \pm $\mathrm{SD} ; n=38$ ), with no significant change in its time course. This 

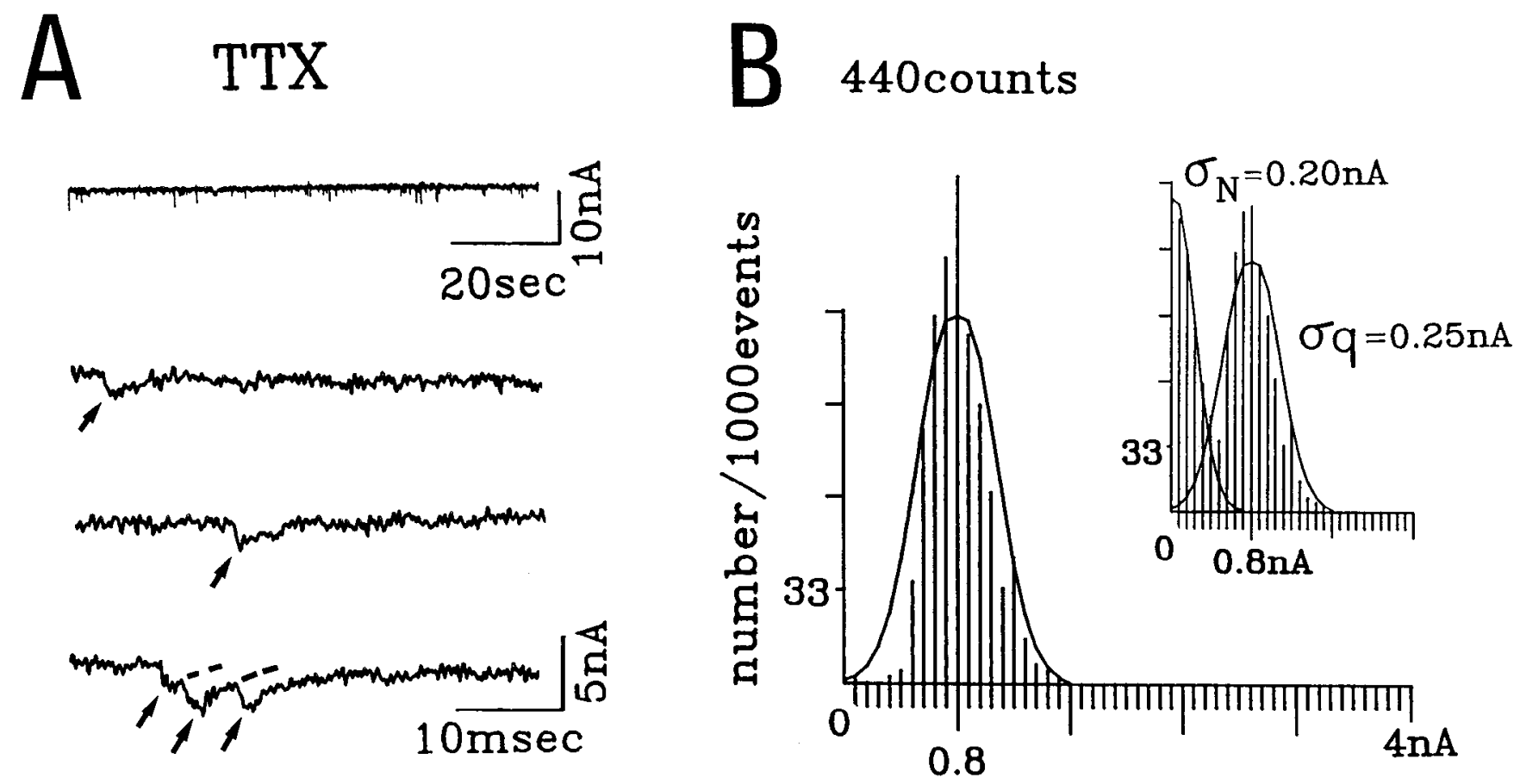

Figure 4. Unimodal distribution of inhibitory quanta. Same experiment as for Figure 3: TTX (20 $\mu \mathrm{M})$ was added on the 3rd ventricle 10 min after the application of fluoxetine. $A$, Spike-dependent synaptic currents were blocked by TTX, as indicated by the disappearance of the M-cell action potential and of the collateral IPSP (not shown), and only single quanta (arrows) were left in isolation (different time scales in the upper and lowest sweeps). $B$, Amplitude distribution of 440 miniature IPSCs recorded in the presence of TTX and best-fitting Gaussian (0.8 $\pm 0.25 \mathrm{nA}$, mean \pm SD). Note the correspondence between the mean size of this peak and the first peak in the amplitude distribution histogram of Figure 3 . Inset, Same histogram, with in addition the amplitude distribution of background fluctuations (positive values only). The latter was fit with half of a Gaussian function (first solid line) centered around 0 and having an SD of $0.2 \mathrm{nA}(\sigma n)$.

facilitation of the population response was unrelated to the degree of chloride loading.

To determine the site of action of 5-HT, we then focused on the spontaneous and evoked components of synaptic noise. For this purpose, the elementary quantal amplitudes were extracted, and the constancy of their amplitude ruled out postsynaptic involvement in the 5-HT-induced facilitation of glycinergic transmission.

\section{Effects of 5-HT on the probability of spontaneous release}

To isolate the spontaneous miniature IPSPs (mIPSPs) from spiketriggered responses, experiments were conducted in the continuous presence of TTX ( $20 \mu \mathrm{M}$, delivered), using current-clamp recordings of chloride-loaded cells. The mIPSPs that thus appeared as depolarizing potentials could be distinguished from occasional excitatory ones (Fig. $2 B l$ ) by their longer rise time and slower decaying phases (Korn et al., 1987). In addition, their blockade by intramuscular injections of strychnine demonstrated that they were glycinergic ( $n=3$; not shown). Within 2-10 min following local injections of 5-HT ( $5 \mathrm{~mm} ; n=10)$, their rate increased by $56 \pm 33.6 \%$ (mean $\pm \mathrm{SD}$; see also Table 1). The amine did not affect their waveform or amplitude distributions (Fig. $2 A 2, B 2$ ), but their average frequency increased progressively reaching a new steady-state level after about 15 min (Fig. 2A3,B3); note also that there is no periodicity to the noise. This elevated rate was maintained throughout the recording period. The overlap between distribution of the synaptic potentials and of the background fluctuations (histograms of Fig. $2 A 2, B 2$ ) suggests that few events were not detected. The SDs of the two distributions ( $\sigma n$ for background and $\sigma q$ for miniatures distributions) were used to estimate the coefficient of variation of the quantum size $\left(\sqrt{\sigma q^{2}-\sigma_{n}^{2} / q}\right)$. In the illustrated case, its value was $11 \%$, which is similar to that reported previously (Korn and Faber, 1990a).

These data indicate that the probability of spontaneous exocytosis of glycinergic vesicles can be locally controlled by $5-\mathrm{HT}$. Interestingly, the use of uptake blockers failed to reproduce this effect $(n=3)$. Possibly TTX may prevent the release of endogenous 5-HT, by directly blocking impulses in serotonergic fibers. Alternatively, it may remove positive modulation of 5-HT release by another neurotransmitter (Tanaka and Tsujimoto, 1981; Auerbach and Lipton, 1982).

\section{Increased probability of evoked release}

Synaptic noise in the $\mathrm{M}$-cell is made up of synaptic responses that have a wide range of amplitudes and occur at various frequencies. As with the TTX-insensitive components, they were blocked by intramuscular injections of strychnine $(4 \mu \mathrm{g} / \mathrm{gm}$ of body weight; $n=3$; not shown). After chloride loading of the M-cell, they appear as inward-going currents (Fig. $3 A, B$ ), which as already stated result either from the release of multiple quanta synchronized by presynaptic impulses or from isolated exocytotic events. The latter are similar in amplitude to the TTXresistant miniatures and may be spike dependent or truly spontaneous (Korn et al., 1987; Korn and Faber, 1990a). In all experiments, a corresponding first peak was clearly distinguished from larger multiple responses, and we confirmed that this minimal component persisted in the presence of TTX. However, it should be noted that because of a number of factors, including the intrinsic variability of the quantum size and low 
Table 1. Size and frequency of spontaneous spike-independent quanta

\begin{tabular}{|c|c|c|c|c|c|c|}
\hline \multirow[b]{2}{*}{$\begin{array}{l}\text { Cell } \\
\text { number }\end{array}$} & \multirow{2}{*}{$\begin{array}{l}\text { Resting } \\
\text { membrane } \\
\text { potential } \\
(\mathrm{mV})\end{array}$} & \multirow[b]{2}{*}{$\begin{array}{l}E_{\mathrm{Cl}} \\
(\mathrm{mV})\end{array}$} & \multirow[b]{2}{*}{$\begin{array}{l}\text { Quantum size } \\
(\mu \mathrm{V})\end{array}$} & \multicolumn{3}{|l|}{ Frequency } \\
\hline & & & & $\begin{array}{l}\text { Control } \\
(\mathrm{Hz} \pm \mathrm{SD})\end{array}$ & $\begin{array}{l}5-\mathrm{HT} \\
(\mathrm{Hz} \pm \mathrm{SD})\end{array}$ & $\begin{array}{l}\text { Increase } \\
(\%)\end{array}$ \\
\hline 1 & -71 & -31 & $79 \pm 17(0.40)$ & $127 \pm 24$ & $215 \pm 32$ & 69 \\
\hline 2 & 78 & 38 & $84 \pm 23(0.42)$ & $110 \pm 41$ & $155 \pm 50$ & 40 \\
\hline 3 & -82 & -66 & $101 \pm 18(1.26)$ & $54 \pm 17$ & $96 \pm 23$ & 77 \\
\hline 4 & -72 & -46 & $65 \pm 20(0.50)$ & $118 \pm 23$ & $161 \pm 27$ & 36 \\
\hline 5 & -79 & -59 & $99 \pm 22(0.76)$ & $70 \pm 22$ & $78 \pm 25$ & 11 \\
\hline 6 & -59 & -19 & $120 \pm 45(0.60)$ & $94 \pm 35$ & $223 \pm 65$ & 137 \\
\hline 7 & -76 & -44 & $102 \pm 30(0.64)$ & $55 \pm 19$ & $97 \pm 25$ & 76 \\
\hline 8 & -65 & -43 & $161 \pm 33(1.46)$ & $33 \pm 15$ & $50 \pm 21$ & 51 \\
\hline 9 & -80 & -24 & $118 \pm 27(0.42)$ & $39 \pm 18$ & $54 \pm 22$ & 38 \\
\hline 10 & -83 & - & $106 \pm 26$ & $44 \pm 17$ & $57 \pm 19$ & 30 \\
\hline
\end{tabular}

Summary of experimental data obtained in presence of TTX. All cells were recorded in current-clamp mode, and for each, $\mathrm{E}_{\mathrm{C}}$ was taken as two times the amplitude of the chloride-mediated collateral IPSP measured before TTX, as in Faber and Korn (1982). The means and SDs of single quanta, $q_{\mathrm{st}}$, are given in millivolts and as percentages (in parentheses) of the full-sized collateral IPSP, $V_{\text {coll }}$. The frequency of miniature events before (control) and after applications of 5-HT was assessed on sweeps of $68 \mathrm{msec}$ duration, for sample periods of at least $10 \mathrm{~min}$; mean rates $\pm \mathrm{SD}$ are given in $\mathrm{Hz}$.

rate of occurrence of larger responses, multiquantal classes were not always apparent. Nevertheless, shifts in the amplitude distributions of inhibitory postsynaptic currents (IPSCs) with the appearance of large values were interpreted in the context of quantal release parameters. The assumption behind this interpretation is that local increases in 5-HT do not alter firing rates of the presynaptic endings, which in these cells are several hundred microns away from the last possible spike generator (Faber and Korn, 1978; see also Discussion).

\section{IPSCs amplitude}

For Figure 3, the amine concentration was elevated by means of fluoxetine applications, and this procedure led to a marked increase in the proportion of large IPSCs as compared to the control ( $B 1, B 2$ vs. $A 1, A 2)$, while the amplitude of the smallest responses (arrows) was not affected, as shown by the constancy of the first peak in the histograms ( $B 3$ vs. $A 3$ ). Similar results were obtained with 5 -HT and imipramine. In each experiment, the mean quantal content was estimated by dividing the mean amplitude of all measured responses by that of the postulated quantum (i.e., the mean of the initial peak). As shown in Table 2 , it was increased by an average of $60 \pm 31 \%(n=10)$. Taken together, these data suggest that 5-HT and the uptake blockers act at terminals to enhance the number of quanta released by a presynaptic spike.

The stability of the quantal amplitude was confirmed with topical administration of TTX at the end of four experiments in this series. As shown in Figure 4, which illustrates data from

Table 2. Amplitude and frequency of spontaneous IPSCs before and after 5-HT

\begin{tabular}{|c|c|c|c|c|c|c|c|c|c|}
\hline \multirow[b]{3}{*}{$\begin{array}{l}\text { Cell } \\
\text { number }\end{array}$} & \multicolumn{5}{|c|}{ Quantal content } & \multicolumn{3}{|l|}{ Frequency } & \multirow[b]{3}{*}{$\begin{array}{l}\text { Inward } \\
\text { rectification } \\
\text { (\%) }\end{array}$} \\
\hline & \multicolumn{2}{|c|}{ Control } & \multicolumn{2}{|l|}{$5-\mathrm{HT}$} & \multirow[b]{2}{*}{$\begin{array}{l}\text { Increase } \\
\text { of mean } \\
(\%)\end{array}$} & \multirow[b]{2}{*}{ Control $(\mathrm{Hz})$} & \multirow[b]{2}{*}{ 5-HT (Hz) } & \multirow[b]{2}{*}{$\begin{array}{l}\text { Increase } \\
(\%)\end{array}$} & \\
\hline & Mean $/ q$ & $\begin{array}{l}\text { Last } \\
\text { peak } \\
\text { (rank) }\end{array}$ & Mean $/ q$ & $\begin{array}{l}\text { Last } \\
\text { peak } \\
\text { (rank) }\end{array}$ & & & & & \\
\hline 11 & 1.11 & 2 & 1.70 & 5 & 53 & 137 & 170 & 24 & 50 \\
\hline 12 & 1.25 & 3 & 1.89 & 5 & 51 & 161 & 257 & 60 & 12 \\
\hline 13 & 1.27 & 3 & 2.65 & 6 & 108 & 45 & 94 & 109 & - \\
\hline 14 & 1.40 & 2 & 2.05 & 5 & 46 & 124 & 197 & 58 & 43 \\
\hline 15 & 1.40 & 3 & 1.94 & 6 & 40 & 227 & 291 & 28 & 40 \\
\hline 16 & 1.40 & 3 & 1.67 & 4 & 19 & 168 & 190 & $13^{*}$ & 63 \\
\hline 17 & 1.40 & 4 & 2.54 & 8 & 87 & 216 & 236 & $9.6^{*}$ & 89 \\
\hline 18 & 1.57 & 4 & 2.05 & 6 & 30 & 104 & 106 & $0^{*}$ & 52 \\
\hline 19 & 1.97 & 5 & 4.30 & 9 & 118 & 413 & 417 & $0^{*}$ & - \\
\hline 20 & 2.53 & 5 & 3.84 & 9 & 52 & 119 & 121 & $0^{*}$ & 10 \\
\hline
\end{tabular}

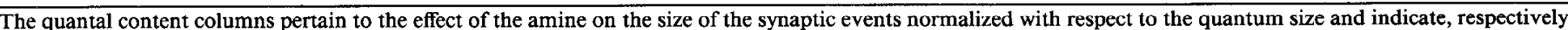

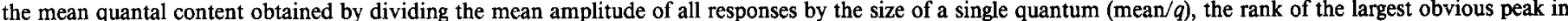

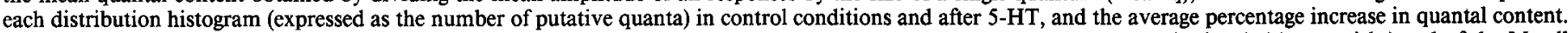

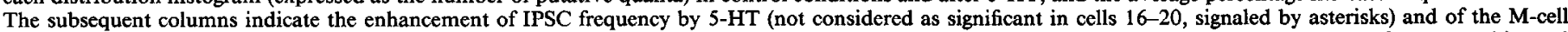

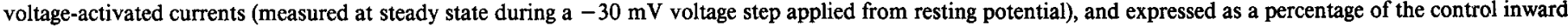
rectifying current. 

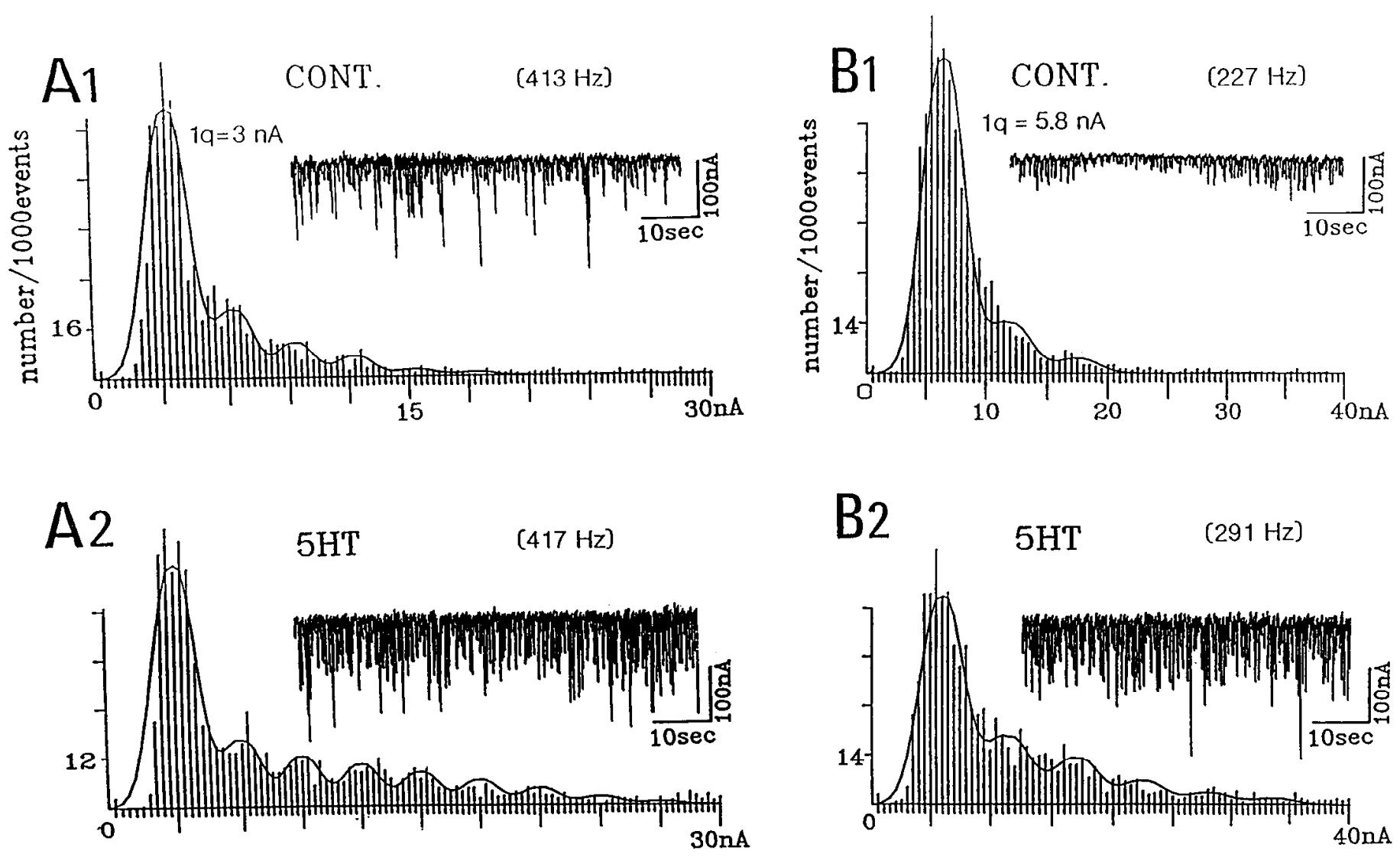

Figure 5. Variable effects of 5-HT on IPSCs frequency: comparison of data obtained from two chloride-loaded cells that exhibited high versus low background activities, the frequencies being as indicated (from cells 15 and 19 of Table 2). Both were voltage clamped at resting potential ( -69 and $-82 \mathrm{mV}$; chopping frequencies, 15 and $21 \mathrm{kHz}$ ). $A 1$ and $B 1$, Amplitude distributions of spontaneous IPSCs recorded in control conditions ( $n=2400$ and 1760 counts, respectively). Successive pcaks were identified with the sum of Gaussian fits regularly spaced around integer multiples of the postulated quantum size $(3 \pm 0.8 \mathrm{nA}$ in $A 1,5.8 \pm 1.5 \mathrm{nA}$ in $B 1$, mean $\pm \mathrm{SD})$. Insets, Sample recordings of corresponding inhibitory synaptic noise. $A 2$ and $B 2$, Increase of the number of peaks in the histograms of events collected after $5-\mathrm{HT}(5 \mathrm{mM} ; n=2424$ and 1852 , respectively, and Gaussian fits using the same parameters as above). Insets, Spontaneous synaptic activity.

the same cell as Figure 3, small responses remained (Fig. 4A) and they had a unimodal amplitude distribution $(B)$, with its mean and SD being similar to those in the compound histograms.

\section{IPSC rate}

The frequency of the events that build up synaptic noise was measured in order to estimate the firing activity in afferent glycinergic interneurons, although it was recognized that this procedure cannot detect failures of release by activated terminals and that evoked single quantum responses cannot be separated from truly spontaneous ones. Changes in IPSC frequency may account for the different levels of control synaptic noise observed in this study, which were quantified before and after 5-HT injections. The expectation was that spontaneous evoked responses would increase primarily in mean amplitude if 5-HT acts locally on the probability of evoked release.

Two different situations were encountered. In the first, which corresponds to cells indicated in Table 2 (asterisks), it appeared that the rate of evoked responses remained almost constant ( $n$ $=5$ ), since the frequency of all events comprising noise was unchanged. This is illustrated in Figure 5, $A 1$ and $A 2$. The striking feature was that the occurrence of large-amplitude IPSCs was increased after 5 -HT ( $A 2$ vs. $A 1$ ) despite the constancy of quantal amplitude. In the second case, which is exemplified by Figure $5, B 1$ and $B 2$, in addition to the changes already described, there was an increase in the overall frequency of all events when measured during equivalent time periods, before and after 5-HT. This effect on frequency seemed restricted to cells (upper cases in Table 2), where the rank of the largest peak in control conditions was low (2-3), an indication that the initial probability of release was low. Its increase by the amine is manifest by the rightward shift of the histogram and the decrease in the relative number of single quanta. This effect on the probability of release may have produced the observed increase in frequency by reducing the number of transmission failures, an effect that could even have been underestimated if there also was an increased rate of spontaneous miniatures, as found after injection of 5-HT in the presence of TTX.

\section{Postsynaptic increase of inward rectification}

Families of voltage step-activated currents were used to investigate the action of 5-HT on the M-cell membrane properties. One minute after application of the amine $(n=25)$ or an uptake blocker $(n=8)$, inward currents elicited by hyperpolarizing steps were increased $(73 \pm 9 \% ; n=33$ ), while outward currents produced by depolarizing steps were unaffected (Fig. $6 A, B$ ). As seen in Figure $6 C$, current-voltage relationships obtained before and 

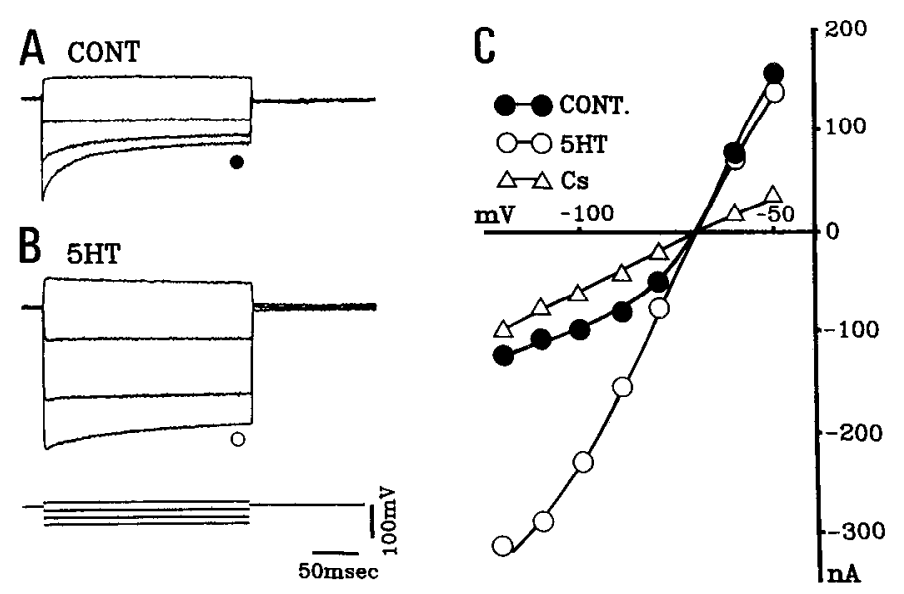

Figure 6. Activation of an inward-rectifying current by 5-HT. M-cell currents recorded in the SEVC mode (chopping frequency, $17 \mathrm{kHz}$ ) with a K-acetate electrode. $A$ and $B$, Families of currents produced by depolarizing $(+10 \mathrm{mV})$ and hyperpolarizing $(-10,-30$, and $-50 \mathrm{mV})$ command pulses, applied from resting potential $(-70 \mathrm{mV})$ in control $(A)$ and $1 \mathrm{~min}$ after local injection $(B)$ of the amine $(2 \mathrm{mM})$. Each trace is an average of four sweeps. $C$, Comparison of steady-state currentvoltage relationships obtained by assessing values at the end of the steps in control conditions (solid circles) and in the presence of 5-HT (open circles) or of cesium ions ( $2 \mathrm{~mm}$; open triangles). The latter was topically applied 9 min after the 5-HT, which induced an inward conductance of $4.2 \mu \mathrm{S}$. Note that the reversal potential was constant and equaled the resting potential (arrow), which is close to $E_{k}$ in the M-cell. (Current recordings and $I / V$ curves not corrected for leak conductances.)

after 5-HT confirm that the amine did elicit an inward rectifying current, which reversed close to the resting potential and which was blocked, along with the control voltage-dependent currents, by cesium ions.

This effect was independent of chloride loading. For Figure 7 , the 5-HT-induced currents were obtained by subtracting the control recordings from those observed after 5 -HT. Results were similar for cells recorded with $\mathrm{KCl}$ (e.g., Fig. 7A1,A2) or $\mathrm{K}$-acetate electrodes (not shown). In both situations, the pharmacologically induced current displayed comparable rectifying properties, showed no tail upon repolarization to resting potential, and also reversed there. It appeared, therefore, to be mainly carried by $\mathrm{K}^{+}$ions. It is distinct from the control inward rectifier since it develops more slowly and does not inactivate during large hyperpolarizations (Fig. $7 A 1$ vs. Fig. $6 A$ ).

\section{Different time courses of pre- and postsynaptic modifications}

In all experiments, the changes in synaptic noise described above occurred within minutes (1-10) following brief local applications of 5-HT in the axon cap. They persisted for $30 \mathrm{~min}$ or more in eight experiments before partial recovery. In one experiment, these effects could be followed for $50 \mathrm{~min}$ (Fig. 8 A1$A 3)$. In that case, the 5-HT-induced shift to the right of the amplitude histogram developed progressively during the recording period, while the increase in frequency reached its maximum $(+30 \%)$ more rapidly (Fig. $8 A 2-C 2$; see also insets). That is, the effect on frequency saturated within $7 \mathrm{~min}$, while IPSC amplitudes continued to grow (Fig. $8 B-C 2$ ). This observation further indicates that the frequency and amplitude effects of 5-HT need not be associated (see cells 16-20 in Table 2). This finding supports the conclusion that 5-HT increases the probability of spike-triggered release locally rather than by enhancing the presynaptic firing rate.
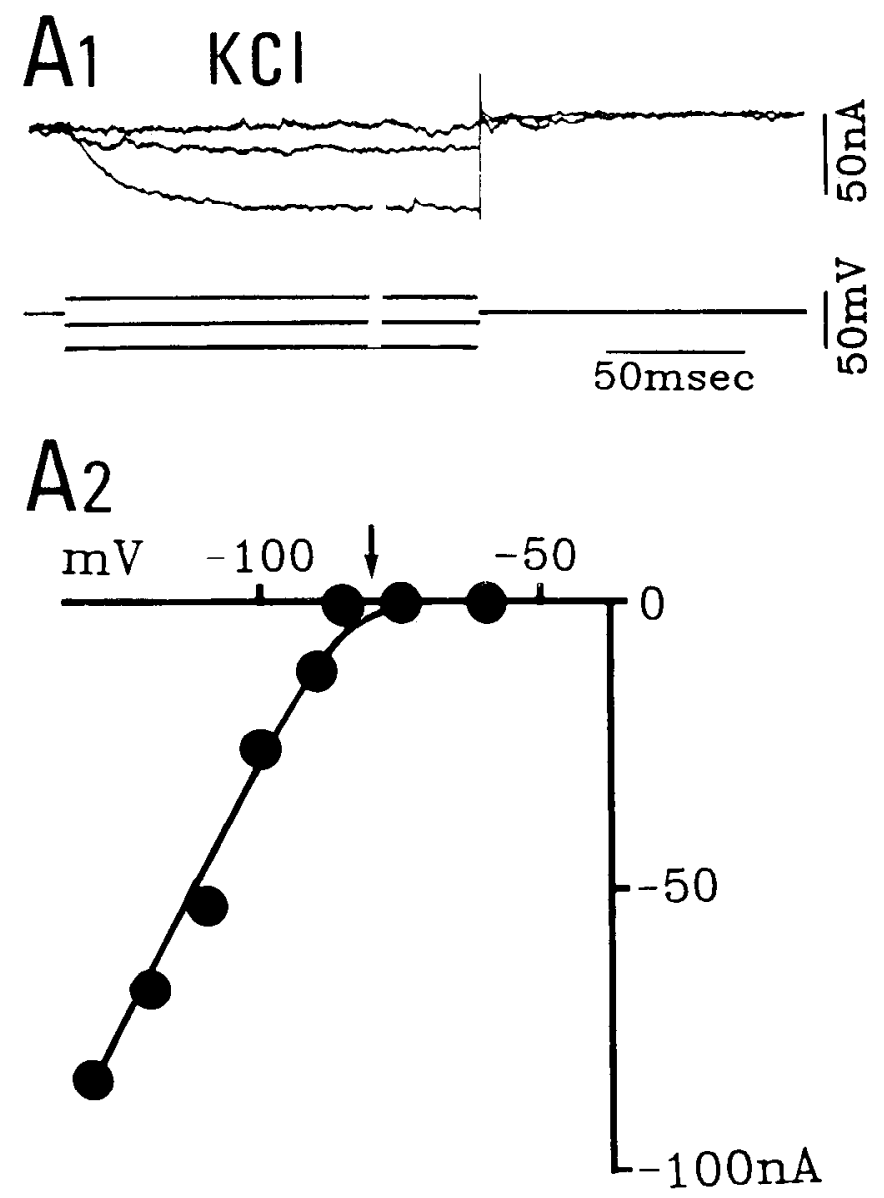

Figure 7. Kinetics of the 5-HT-induced rectification. $A I$ and $A 2$, Voltage-dependent currents induced by $5-\mathrm{HT}(5 \mathrm{mM})$ in a chloride-loaded M-cell $\left(E_{\mathrm{Cl}^{-}} \sim-50 \mathrm{mV}, \mathrm{SEVC}\right.$ recording mode; chopping frequency, $20 \mathrm{kHz}$ ). $A 1$, Current responses to $+10,-10$, and $-30 \mathrm{mV}$ command pulses applied from resting potential $(-78 \mathrm{mV})$. Each trace (average of four sweeps) was obtained by subtracting the voltage-activated current in control conditions from the corresponding one observed $10 \mathrm{~min}$ after onset of 5-HT effect. $A 2$, Steady-state $I / V$ curve of the 5-HT-induced current, determined by the same procedure. In the hyperpolarizing direction, the steady-state currents were directly proportional to the voltage steps, yielding a conductance of $1.85 \mu \mathrm{S}$. The arrow indicates resting membrane potential.

In contrast, the postsynaptic enhancement of inward rectification at the M-cell membrane was only transitory (Fig. 8A3C3). It was fast in onset, beginning within seconds following drug injections and developing over the next 1-15 min. After that, it began to reverse despite a persistent increase in mean IPSP amplitude. In a few experiments $(n=2), 5$-HT produced this effect without altering the spontaneous synaptic noise, a confirmation that the two actions of the amine are independent.

\section{Discussion}

As shown in this article, 5-HT produces two independent effects at the M-cell level. One is postsynaptic, namely, an increase in inward rectification. The other is presynaptic, a potentiation of glycinergic inhibition. The endogenous amine, whose concentration can be raised in the extracellular space by uptake blockers, as in the raphe nucleus (Bobker and Williams, 1990b), is equally effective. 

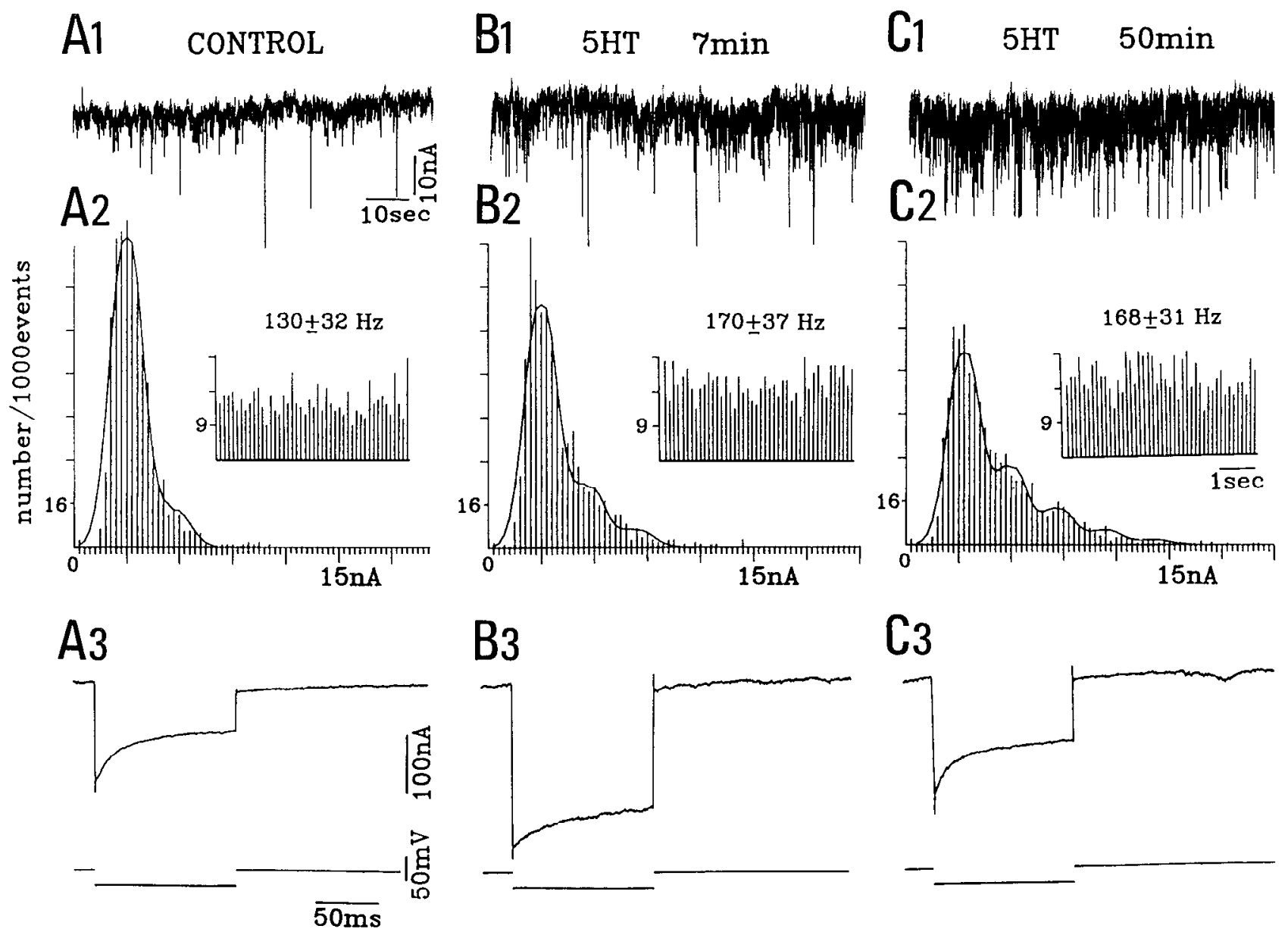

B3

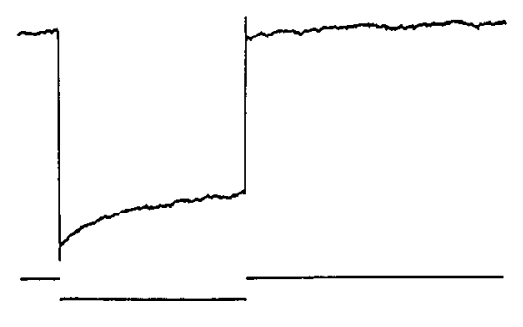

C3

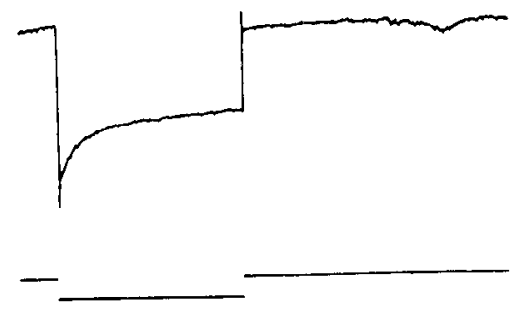

Figure 8. Temporal dissociation of pre- and postsynaptic effects of 5-HT. Recordings were obtained in the SEVC mode at resting membrane potential $(-83 \mathrm{mV}$; chopping frequency, $22 \mathrm{kHz}) . A I, B I$, and $C 1$, Spontaneous inhibitory synaptic noise in control and 7 and $50 \mathrm{~min}$ after a brief injection of 5-HT in the axon cap $(5 \mathrm{~mm})$. Same calibrations for all sweeps. $A 2, B 2$, and $C 2$, Corresponding histograms of IPSC amplitude distributions, which were measured throughout $10 \mathrm{sec}$ time periods. The successive peaks of the Gaussian fits had integral multiple values of $3 \mathrm{nA}$ as respective means, and the same SDs $(0.8 \mathrm{nA})$. Insets, Frequency of occurrence of IPSCs, assessed and presented as in Figure 5 , with the indicated mean $\pm \mathrm{SD}$ values. $A 3, B 3$, and $C 3$, Average inward currents $(n=4)$ elicited by a $-30 \mathrm{mV}$ voltage step applied from resting potential, in the same conditions as above. Note that soon after 5-HT, the increase of IPSC rate and amplitude was accompanied by a marked enhancement of the $\mathrm{K}^{+}$ inward-rectifying current but that at $50 \mathrm{~min}$ the latter effect was partially reversed while the increased transmitter release persisted. From cell 11 of Table 2 .

\section{Activation of an inward $K^{+}$current}

This action resembles that described for numerous preparations, such as the Aplysia R15 neuron (Benson and Levitan, 1983), hippocampal pyramidal cells (Yakel et al., 1988), and raphe neurons (Williams et al., 1988). The current activates slowly during hyperpolarizing voltage steps, does not inactivate, and is sensitive to $\mathrm{Cs}^{+}$ions. It appears different from the $\mathrm{K}^{+}$inward rectifier in control conditions, which exhibits faster activation and inactivates (Faber and Korn, 1986), but modifications of the latter by the amine cannot be ruled out.

With the resolution of our technique, 5-HT did not induce any significant outward current, which raises questions concerning the physiological significance of this conductance. The resting potential of the $\mathrm{M}$-cell is quite high (Furukawa and Furshpan, 1963; Faber and Korn, 1978), and since $F_{\mathrm{Cl}}$ is close to the same level, electrical inhibition exerted through field effects by presynaptic afferents (Faber and Korn, 1989) is the only occasion when the M-cell membrane potential goes more negative. It is unlikely that the amplitude of this short-lasting hy- perpolarization, normally less than $10 \mathrm{mV}$, is sufficient to activate the inward rectifier.

\section{Facilitation of spontaneous release}

In the presence of TTX, an increased frequency of mIPSPs was only observed if 5-HT was applied close (i.e., within $30 \mu \mathrm{m}$ ) to the M-cell membrane. In contrast, this enhancement probably did not occur in absence of the toxin since, in some experiments the total frequency remained constant (Table 2). Similarly, in other preparations, TTX reduces the rate of spontaneously occurring quanta (Landau, 1969), which could be maximal in normal conditions, thereby precluding any possible enhancement by other factors. Earlier observations suggested that TTX might have such consequences in the M-cell (Korn and Faber, 1990a). This hypothesis may apply to the sensorimotor synapse of Aplysia, where neurotransmitter modulation of spontaneous miniatures has been documented only with external media having low calcium and TTX (Dale and Kandel, 1990). 


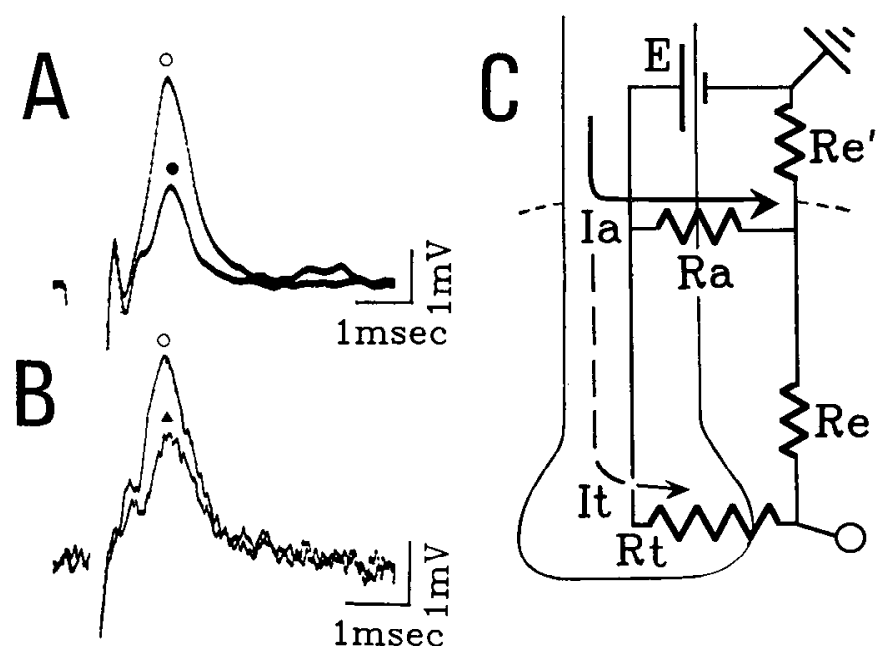

Figure 9. Involvement of $\mathrm{K}^{+}$channels at the level of presynaptic terminals. $A$ and $B$, Evidence that TEA ions ( $1 \mathrm{~mm} ; A$ ) and 5-HT ( 5 mM; $B)$ applied in proximity of the M-cell membrane reduce the extracellularly recorded presynaptic volley produced by activation of commissural interneurons. In both experiments, there was a simultaneous increase of inhibitory synaptic noise (not shown). Field potentials were recorded in the axon cap following stimulation of the contralateral VIIIth nerve, in control conditions (open circles), and after drug injection (solid symbols). $C$, Analog diagram accounting for this effect. In commissural and collateral inhibitory interneurons, the spike generator $(E)$ is located outside the axon cap and passively conducted action current (It and Ia) flow across the terminal $(R t)$ and preterminal $(R a)$ resistances. Increasing $R t$ by blocking $\mathrm{K}^{+}$channcls forces more current to exit proximally through $R a$, therefore reducing the extracellular voltage drop at a terminal recordings site (open circle). $R e$ and $R e^{\prime}$ represent corresponding extracellular resistances; note that the former is within the axon cap and is consequently larger than the latter.

\section{Facilitation of evoked release}

Comparison of the structure of synaptic noise before and after 5-HT provides strong albeit indirect evidence that this transmitter increases the probability of release at glycinergic terminals. Inhibitory noise in the M-cell represents the sum of the activities of individual presynaptic interneurons. For each connection, the release process can be described by a simple binomial model with two parameters: $n$, the number of quantalreleasing units, which corresponds to the number of active zones issued by the presynaptic cell, and $p$, the average probability of release at each site (Korn et al., 1981, 1982; Triller and Korn, 1982). Thus, synaptic noise can be treated as a sum of individual release functions, plus the excess of single quanta due to spontaneous exocytosis (Korn et al., 1987). Prior curve fitting of probability density histograms such as those presented in this report suggested that the afferents that produce noise have a low probability of release. Consequently, a significant fraction of the single quanta is triggered by presynaptic spikes (Korn and Faber, 1990a), and there are failures of evoked release that cannot be detected. It follows that in preparations where the rank of the largest peak is small, there is also a sizable percentage of transmission failures, a conclusion that is not model dependent.

Following 5-HT injections, the shift to the right of the amplitude distributions implies that there is an increase in the number of multiquantal responses and a decrease in the number of failures and single quantum responses, a process most likely brought about by increasing $p$. The reduction of failures is a process that is likely to saturate: in that case, there would no longer be an increase to frequency as in the case of Figure $8 C$. The alternative explanation that $5-\mathrm{HT}$ increases $n$ by causing multiquantal release at individual active zones is less likely, particularly since multiple events would not be detected as integral multiples in limited postsynaptic receptor clusters (Faber et al., 1985; Triller et al., 1990). Finally, it has been shown that at the level of the M-cell, some connections are functionally silent, as a result of a lack of responsiveness of the receptors to the released transmitter (Faber et al., 1990; Korn and Faber, 1990b), which can be revealed by glycine. A relief of this block by 5 -HT would alter synaptic noise in the manner reported here, a condition where this type of analysis could not distinguish between pre- and postsynaptic loci (see also Bekkers and Stevens, 1990).

In the hippocampal slice, exogenous 5-HT has recently been shown to enhance inhibition of CA1 neurons due to somatic excitation of GABAergic interneurons (Guy and Ropert, 1990). Our data exclude such a comparable remote effect for the following reasons: (1) injections in the axon cap, but at a distance of 50-100 $\mu \mathrm{m}$ above the M-cell, did not affect glycinergic transmission. (2) 5-HT is unlikely to act at a distance from the injection site due to high uptake activity in the M-cell preparation. Indeed, 5-HT (up to $10 \mathrm{~mm}$ ) applied in the third ventricle affected neither the M-cell inward rectification nor its glycincrgic synaptic responses, whereas uptake blockers similarly applied on the brain surface did produce both pre- and postsynaptic effects. (3) In several experiments, the frequency of evoked responses was not affected by $5-\mathrm{HT}$, an indication that the presynaptic firing pattern was unaltered by the amine.

\section{Afferent volley and possible ionic mechanisms}

In several preparations, 5-HT increases the calcium influx associated with an action potential by either activating calcium conductances (Paupardin-Tritsch et al., 1986) or closing potassium channels (Siegelbaum et al., 1982). These two mechanisms often result in the prolongation of the action potential, which is not the case in M-cell afferents, as shown by extracellular recordings of the afferent volley in the axon cap (Fig. 9A,B). This field potential was reduced in both amplitude, by about $50 \%$, and half-width, by about $10 \%$, by potassium channel blockers $(A)$ and 5-HT $(B)$. Its shape and amplitude are determined by the passive properties of the axonal and terminal membranes, and it is established that for a single presynaptic cell, its duration matches that of the afferent action potential (Korn and Faber, 1975). Thus, any spike prolongation would presumably have been detected.

The reduction of the size of the afferent volley suggests that 5-HT increased the terminal resistance, probably by blocking some $\mathrm{K}^{+}$conductances since, as mentioned, a similar effect was produced by local injections of $\mathrm{K}^{+}$channel blockers [cesium: 2 $5 \mathrm{mM} ; n=7$; not shown; tetraethylammonium (TEA): $1 \mathrm{nM} ; n$ $=5$ ]. As shown by the equivalent diagram of Figure $9 C$, a closure of the presynaptic $\mathrm{K}^{+}$channels would increase terminal input resistance and therefore lead to a larger transmembrane voltage drop during an action potential. This increased depolarization would be more effective in opening calcium channels, thereby producing a greater $\mathrm{Ca}^{2+}$ influx as the spike repolarizes. It remains to be shown whether this modification, or another effect such as one mediated by a second messenger, leads to an enhanced probability of transmitter release.

These data indicate that glycinergic transmission is modulated in the CNS. In peripheral systems, other inhibitory synapses are 
locally controlled by neurotransmitters, such as the fast GABAergic IPSCs by 5-HT at the crayfish neuromuscular junction (Finger and Martin, 1984) and the slow catecholaminergic response by enkephalin in frog sympathetic neurons (Wouters and Van den Bercken, 1979). In contrast to most central studies of presynaptic regulation, which have relied on in vitro approaches (for review, see Chesselet, 1984), our results with uptake blockers and previous descriptions of morphological substrates for the pre- and postsynaptic actions of 5-HT (Gotow et al., 1989) suggest that this fine-tuning of inhibitory transmission is operational in vivo. It could mediate behavioral regulation of the threshold for the escape reflex and, for example, underlie the decreased probability of the M-cell firing, during habituation (Eaton and Hackett, 1984).

\section{References}

Alger BE, Nicoll RA (1980) Spontaneous inhibitory postsynaptic potentials in hippocampus; mechanism for tonic inhibition. Brain Res 200:195-200.

Auerbach S, Lipton P (1982) Vasopressin augments depolarizationinduced release and synthesis of serotonin in hippocampal slices. $J$ Neurosci 2:477-482.

Bekkers JM, Stevens CF (1990) Presynaptic mechanism for long-term potentiation in the hippocampus. Nature 346:724-729.

Benson JA, Levitan IB (1983) Serotonin increases an anomalous rectifying $\mathrm{K}^{+}$current in the Aplysia neuron R15. Proc Natl Acad Sci USA 80:3522-3525.

Berger AJ, Takahashi T (1990) Serotonin enhances a low-voltageactivated calcium current in rat spinal motoneurons. J Neurosci 10: 1922-2028.

Bobker DH, Williams JT (1989) Serotonin augments the cationic current $I_{h}$ in central neurons. Neuron 2:1535-1540.

Bobker DH, Williams JT (1990a) Ion conductances affected by $5-\mathrm{HT}$ receptor subtypes in mammalian neurons. Trends Neurosci 13:169173.

Bobker DH, Williams JT (1990b) Serotonin-mediated inhibitory postsynaptic potential in guinea-pig prepositus hypoglossi and feedback inhibition by serotonin. J Physiol (Lond) 422:447-462.

Chesselet MF (1984) Presynaptic regulation of neurotransmitter release in the brain. Neuroscience 12:347-375.

Colino A, Halliwell JV (1987) Differential modulation of three separate K-conductances in hippocampal CAl neurons by serotonin. Nature 328:73-77.

Dale N, Kandel ER (1990) Facilitatory and inhibitory transmitters modulate spontaneous transmitter release at cultured Aplysia sensorimotor synapses. J Physiol (Lond) 421:203-222.

Dixon D, Atwood HL (1989a) Phosphatidylinositol system's role in serotonin-induced facilitation at the crayfish neuromuscular junction. J Neurophysiol 62:239-246.

Dixon D, Atwood HL (1989b) Conjoint action of phosphatidylinositol and adenylate cyclase systems in serotonin-induced facilitation at the crayfish neuromuscular junction. J Neurosci 62:1251-1259.

Eaton RC, Hackett JT (1984) The role of the Mauthner cell in faststarts involving escape in teleost fishes. In: Neural mechanisms of startle behavior (Eaton RC, ed), pp 213-266. New York: Plenum.

Eccles JC, Eccles RM, Iggo A, Lundberg A (1961) Flectrophysiological investigations of Renshaw cells. J Physiol (Lond) 159:461-478.

Faber DS, Korn H (1978) Electrophysiology of the Mauthner cell: basic properties, synaptic mechanisms, and associated network. In: Neurobiology of the Mauthner cell (Faber DS, Korn H, eds), pp 47132. New York: Raven.

Faber DS, Korn H (1982) Transmission at a central inhibitory synapse. I. Magnitude of unitary postsynaptic conductance change and kinetics of channel activation. J Neurophysiol 48:654-678.

Faber DS, Korn H (1986) Instantaneous inward rectification in the Mauthner cell: a postsynaptic booster for excitatory inputs. Neuroscience 9:1037-1043.

Faber DS, Korn H (1989) Electrical field effects: their relevance in central neural networks. Physiol Rev 69:821-863.

Faber DS, Funch PG, Korn H (1985) Evidence that receptors mediating central synaptic potentials extend beyond the postsynaptic density. Proc Natl Acad Sci USA 82:3504-3508.
Faber DS, Lin JW, Korn H (1990) Silent synaptic connections and their modifiability. Ann NY Acad Sci, in press.

Finger W, Martin C (1984) Giant inhibitory miniature currents in crayfish muscle in the presence and absence of extracellular sodium and serotonin. Neurosci Lett 51:127-132.

Furshpan EJ, Furukawa T (1962) Intracellular and extracellular responses of the several regions of the Mauthner cell of the goldfish. J Neurophysiol 25:732-771.

Furukawa T, Furshpan EJ (1963) Two inhibitory mechanisms in the Mauthner neurons of goldfish. J Neurophysiol 26:140-176.

Glusman S, Kravitz E (1982) The action of serotonin on excitatory nerve terminals in lobster nerve-muscle preparations. J Physiol (Lond) 325:223-241.

Gotow T, Triller A, Korn H (1989) Differential distribution of serotonergic inputs on the goldfish Mauthner cell. J Comp Neurol 292: 255-268.

Goy MF, Kravitz EA (1989) Cyclic AMP only partially mediates the actions of serotonin at lobster neuromuscular junctions. J Neurosci 9:369-379.

Granit R, Phillips CG (1956) Excitatory and inhibitory processes acting upon individual Purkinje cells of the cerebellum in cats. J Physiol (Lond) 133:520-547.

Guy N, Ropert N (1990) Serotonin facilitates GABAergic transmission on hippocampal CA1 neurones in vitro. J Physiol (Lond) 423:94p.

Hounsgaard J, Kiehn O (1989) Serotonin-induced bistability of turtle motoneurones caused by a nifedipine sensitive calcium plateau potential. J Physiol (Lond) 414:265-282.

Hounsgaard J, Hultborn H, Jespusen B, Kiehn O (1988) Bistability of motoneurones in the decerebrated cat and in the acute spinal cat after intravenious 5-hydroxy-tryptophan. J Physiol (Lond) 405:345367.

Kandel ER, Klein M, Bailey CH, Hawkins RD, Castellucci VF, Lubit BW, Schwartz JH (1981) Serotonin, cyclic AMP, and the modulation of the calcium current during behavioral arousal. In: Serotonin, neurotransmission and behavior (Jacobs BL, Gelperin A, eds), pp 211-254. Cambridge, MA: MIT Press.

Katz B, Miledi R (1963) A study of spontaneous miniature potentials in spinal motoneurons. J Physiol (Lond) 168:389-422.

Klein M, Kandel ER (1978) Presynaptic modulation of voltage-dependent $\mathrm{Ca}^{2+}$ current: mechanism for behavioral sensitization in Aplysia californica. Proc Natl Acad Sci USA 75:3512-3516.

Klein M, Kandel ER (1980) Mechanism of calcium current modulation underlying presynaptic facilitation and behavioral sensitization in Aplysia. Proc Natl Acad Sci USA 77:6912-6916.

Klein M, Camardo J, Kandel ER (1982) Serotonin modulates a specific potassium current in the sensory neurons that show presynaptic facilitation in Aplysia. Proc Natl Acad Sci USA 79:5713-5717.

Korn H, Faber DS (1975) An electrically mediated inhibition in goldfish medulla. J Neurophysiol 38:452-471.

Korn H, Faber DS (1987) Regulation and significance of probabilistic release mechanisms at central synapses. In: Synaptic function (Edelman, Gall, Cowan, eds), pp 57-108. New York: Wiley.

Korn H, Faber DS (1990a) Transmission at a central inhibitory synapse. IV. Quantal structure of synaptic noise. J Neurophysiol 63:198222.

Korn H, Faber DS (1990b) Quantitative electrophysiological studies and modelling of central glycinergic synapses. In: Glycine neurotransmission (Ottersen OP, Storm-Mathisen J, eds), pp 139-170. Chichester, England: Wiley.

Korn H, Mallet A, Triller A, Faber DS (1981) Fluctuating responses at a central synapse: $n$ of binomial fit predicts number of stained presynaptic boutons. Science 213:898-901.

Korn H, Mallet A, Triller A, Faber DS (1982) Transmission at a central inhibitory synapse. II. Quantal description of release, with a physical correlate for binomial $n$. J Neurophysiol 48:679-707.

Korn H, Burnod Y, Faber DS (1987) Spontaneous quantal currents in a central match predictions from binomial analysis of evoked responses. Proc Natl Acad Sci USA 84:5981-5985.

Landau EM (1969) The interaction of presynaptic polarization with calcium and magnesium in modifying spontaneous transmitter release from mammalian motor nerve terminals. J Physiol (Lond) 203:281299

Mintz I, Korn H (1989) Focal application of serotonin enhances spontaneous and evoked components of inhibitory synaptic noise. Soc Neurosci Abstr 15:484.

Mintz I, Gotow T, Triller A, Korn H (1989) Effect of serotonergic 
afferents on quantal release at central inhibitory synapses. Science 245:190-192.

Paupardin-Tritsch D, Hammond C, Gerschenfeld HM, Nairn AC, Greengard P (1986) C-GMP dependent protein kinase enhances $\mathrm{Ca}^{2+}$ current and potentiates the serotonin-induced $\mathrm{Ca}^{2+}$ current increase in snail neurones. Nature 323:812-814.

Sah DWY (1990) Neurotransmitter modulation of calcium current in rat spinal cord neurons. J Neurosci 10:136-141.

Siegelbaum SA, Camardo JS, Kandel FR (1982) Serotonin and cyclic AMP close single $\mathrm{K}^{+}$channels in Aplysia sensory neurones. Nature 299:413-417.

Tanaka S, Tsujmoto (1981) Somatostatin facilitates the serotonin release from rat cerebral cortex, hippocampus and hypothalamus slices. Brain Res 208:219-222.

Triller A, Korn H (1982) Transmission at a central inhibitory synapse.
III. Ultrastructure of physiologically identified and stained terminals. J Neurophysiol 48:708-736.

Triller A, Seitanidou T, Franksson O, Korn H (1990) Size and shape of glycine receptor clusters in a central neuron exhibit a somatodendritic gradient. New Biol 2:637-641

Williams JT, Colmers WF, Pan ZZ (1988) Voltage- and ligand-activated inwardly rectifying currents in dorsal raphe neurons in vitro. J Neurosci 8:3499-3506.

Wouters W, Van den Bercken (1979) Hyperpolarization and depression of slow synaptic inhibition by enkephalin in frog sympathetic ganglion. Nature 277:53-54.

Yakel JL, Trussell LO, Jackson MB (1988) Three serotonin responses in cultured mouse hippocampal and striatal neurons. J Neurosci 8: 1273-1285. 